\title{
AS AULAS DE BALÉ CLÁSSICO EM UMA UNIVERSIDADE DA MELHOR IDADE EM CAMPO GRANDE - MS
}

\author{
Gisele Aparecida Ferreira Martins \\ Universidade Católica Dom Bosco \\ giseleaparecida.ef@hotmail.com
}

\begin{abstract}
Resumo
O objetivo desta pesquisa foi relatar a experiência de alunas que frequentam as aulas de balé clássico oferecidas em uma universidade da melhor idade na cidade de Campo Grande- Mato Grosso do Sul(MS). De abordagem qualitativa, utilizaram-se entrevistas semiestruturadas para identificar o significado das aulas de balé e as contribuições dessa atividade na qualidade de vida de onze alunas da instituição. A base teórica foi construída com os autores: Ferreira et.al (2009), Leal e Haas (2006), Martins (2014), R. F. Marbá, et. al. (2016) e Witter et.al (2013), que relataram alguns benefícios das aulas de dança entre eles a melhoria da aptidão funcional e física e a diminuição dos efeitos deletérios do avanço da idade cronológica. Todas as alunas declararam estar realizando um sonho de menina, sentindo-se mais "Jovens", que perderam a timidez e o maior fator de satisfação foi subir em um palco e apresentar as coreografias aprendidas durante as aulas.
\end{abstract}

Palavras Chave: Balé Clássico. Dança. Envelhecimento Ativo. Qualidade de Vida.

\section{THE CLASSICAL BALLET CLASSES AT A UNIVERSITY OF THE THIRD AGE IN CAMPO GRANDE - MS}

\begin{abstract}
The objective of this research is to report the experience of students attending classical ballet classes offered at a university of the best age in the city of Campo Grande - MS. From a qualitative approach, she used semi-structured interviews to identify the meaning of ballet classes and the contributions of this activity to the quality of life of eleven students of the institution. The theoretical basis was constructed with the authors: Ferreira et.al (2009), Leal and Haas (2006), Martins (2014), R. F. Marbá, et. al. (2016) and Witter et al (2013), who reported some benefits of dance classes among them improving functional and physical fitness and reducing the deleterious effects of advancing chronological age. All the students declared that they were fulfilling a girl's dream, feeling more "young", that they lost their shyness and the biggest factor of satisfaction was to go up on stage and present the choreographies learned during the lessons.

Keywords: Classical Ballet. Dance. Active Aging. Quality of Life.

\section{LAS CLASES DE BALLET CLÁSICO EN UNA UNIVERSIDAD DE LA TERCERA EDAD EN CAMPO GRANDE - MS}

\section{Resumen}

El objetivo de esta investigación es relatar la experiencia de alumnas que frecuentan las clases de ballet clásico ofrecidas en una universidad de la mejor edad en la ciudad de Campo Grande-MS. De abordaje cualitativo, utilizó entrevistas semiestructuradas para identificar el significado de las clases de ballet y las contribuciones de esa actividad en la calidad de vida de once alumnas de la institución. La base teórica fue construida con los autores: Ferreira et.al (2009), Leal y Haas (2006), Martins (2014), R. F. Marbá, et. al. (2016) y Witter et al. (2013), que relataron algunos beneficios de las clases de danza entre ellos la mejora de la aptitud funcional y física y la disminución de los efectos deletéreos del avance de la edad cronológica. Todas las alumnas declararon estar realizando un sueño de niña, sintiéndose más "Jóvenes", que perdieron la timidez y el mayor factor de satisfacción fue subir en un escenario y presentar las coreografías aprendidas durante las clases. Palabras clave: Ballet Clásico. Danza. Envejecimiento Activo. Calidad de Vida. 


\section{INTRODUÇÃO}

A opção por uma pesquisa sobre as aulas de balé clássico oferecidas em uma universidade da melhor idade justifica-se pelos benefícios que essa atividade proporciona na qualidade de vida das alunas que a praticam. Mas existem outros motivos que influenciaram esta opção pela pesquisa. Um deles advém da experiência como bailarina e da formação em balé clássico da professora do grupo.

A professora iniciou sua carreira no balé ao frequentar aulas de balé clássico e Jazz aos onze anos de idade e aos quatorze anos de idade auxiliava as professoras nas aulas com as turmas iniciantes. Possui graduação em educação física, e durante esta já atuava como professora de balé clássico para turmas de crianças e adultos. Posterior à graduação veio o curso de especialização em dança, o convite para trabalhar na graduação em educação física e lecionar disciplinas na especialização onde, manteve contato com adultos que contavam do sonho de infância de participar das aulas de ballet. Outro motivo impulsionador tem sido a vivência da professora nas aulas de balé clássico da Universidade da melhor idade, um novo desafio profissional cujo trabalho teve inicio em fevereiro de 2017.

Em relação à pesquisa, estudos veem demonstrando a preocupação com a qualidade de vida das pessoas idosas. No Brasil existem várias instituições preocupadas com a qualidade de vida das pessoas que estão nessa etapa do ciclo de vida. Estas instituições, através de programas sociais e educativos, oferecem atividades que ajudam os idosos a se manterem ativos, nos aspectos físico e mental, e assim envelhecer com qualidade de vida, conforme nos conta Leal e Haas (2006).

A dança é uma das atividades oferecidas para o público da melhor idade e "é uma arte que significa expressões gestuais e faciais através de movimentos corporais, emoções sentidas a partir de determinado estado de espírito" (Hass e Garcia, 2006, p.139). Essa atividade "vem contribuir significativamente na melhora e/ou manutenção de várias dimensões que estão inseridas no termo "qualidade de vida", entre elas a integração social, a adaptação às condições preexistentes e a aptidão funcional" (WITTER, et. al, 2013, pg. 192).

O balé clássico é um estilo de dança que tem os seguintes aspectos:

O ballet é arquitetura sob forma de dança. É também o produto da fusão de outras artes (música, pintura e poesia) com a dança [...] o que distingue a dança pura do ballet é que a primeira é fundamentalmente instintiva, enquanto o ballet é composto de passos diferentes, de ligações, de gestos e de figuras previamente elaboradas para um ou mais intérpretes (Achcar, 1980, p.41). 
Escrever esta pesquisa representa uma necessidade e a vontade de dar voz a uma série de indagações acerca da dança como atividade oferecida para pessoas da melhor idade e da atuação como professora de balé para alunas da melhor idade. Algumas dessas perguntas ecoam com mais intensidade. A principal delas diz respeito ao significado das aulas de balé na vida das alunas da Universidade da Melhor Idade. Em torno dessa questão, articulam-se outras perguntas necessárias até para a compreensão daquela, como: Qual a importância que as alunas dão as aulas de balé? Como as alunas se sentem ao praticar o balé levando em consideração a idade em que elas se encontram? Quais as contribuições das aulas de balé na qualidade de vida das alunas?

Para responder essas perguntas o objetivo delineado para a pesquisa foi o de relatar a experiência de alunas que frequentam as aulas de balé clássico oferecidas em uma universidade da melhor idade (UMI) na cidade de Campo Grande- MS.

A UMI foi criada no ano de 1998 como um projeto comunitário que teve origem a partir da dissertação de mestrado de uma professora da instituição. No ano de 2002, foram propostas inovações e maior abertura para que os acadêmicos dos cursos de Graduação da universidade, bem como para os professores da instituição, tivessem o conhecimento acerca do trabalho com a melhor idade, despertando o interesse em estudos voltados ao envelhecimento humano. Sendo assim, a UMI deixa de ser um projeto e passa a ser um Programa Institucional com corpo técnico especializado, totalmente profissional que tem respaldo Político de cunho social e Educacional. Baseado na linha francesa conforme citado por Cachioni (2003), a UMI proporciona a interação entre idosos e alunos da graduação. Sendo assim, a UMI, passar a ser um Programa da Universidade a partir do ano de 2005.

$\mathrm{Na}$ grade curricular das atividades oferecidas na UMI existem as disciplinas obrigatórias e as atividades optativas. Dentre as atividades optativas estão às aulas de balé clássico, que se iniciaram no dia 01 de fevereiro de 2017. Foi criado, então, o grupo de balé sênior, que é uma adaptação do ballet clássico pensado no físico e na idade das alunas que o praticam. São alguns dos benefícios das aulas de balé sênior: o conhecimento de sensações positivas e prazerosas, a promoção da socialização bem como proporcionar ao indivíduo que a prática, força muscular, estética corporal e autoestima.

\footnotetext{
O balé é uma forma de ensino que não se resume simplesmente em aquisição de habilidades, sua prática promove o desenvolvimento dos estímulos táteis, visuais, auditivos, afetivos, cognitivos e motores. Como prática corporal, pode ser entendido como expressão de vida e linguagem social, como manifestação cultural e interação com o meio. Ele não deve ser considerado apenas um passatempo e pode contribuir no aprimoramento de padrões fundamentais do movimento, na formação artística e integração social (MARTINS, 2014, p. 285).
} 
As aulas de balé clássico em uma universidade da melhor idade em Campo Grande - MS

Ao iniciar as aulas de balé sênior na UMI, houve pouca aceitação por parte das alunas que achavam a professora jovem, e diziam que seria uma tarefa árdua ensinar mulheres idosas, ou ainda que balé era "coisa de criança". Em todas as sequências coreográficas propostas durante as aulas havia uma resistência por parte das alunas. Até que chegou o dia da primeira apresentação, em comemoração ao dia das mães e realizada no auditório da Universidade. As alunas apresentaram uma valsa clássica e foram aplaudidos de pé. Os convidados se emocionaram e, a partir desse dia, mais que um voto de confiança, quase quarenta alunas se inscreveram nas turmas.

Em seguida começaram a surgir convites para apresentações em diversos locais e até em outras cidades e estados. Assim, novas coreografias foram criadas e houve uma significativa diminuição das faltas das alunas nas aulas, nas queixas de problemas de saúde e elevou-se a autoestima das alunas do grupo.

\section{MATERIAIS E MÉTODOS}

Os sujeitos da pesquisa aqui descritos são onze alunas que frequentam as aulas de balé sênior, como disciplina optativa, em uma Universidade da melhor idade, oferecida como um programa institucional em uma Universidade localizada na cidade de Campo Grande - MS. As aulas acontecem às terças-feiras e quintas-feiras, das $15 \mathrm{~h} 00 \mathrm{~min}$ ás $17 \mathrm{~h} 00 \mathrm{~min}$ ficando facultativa, às alunas, a opção de participar das duas horas ininterruptas de aula ou de apenas uma hora.

A pesquisa, de abordagem qualitativa, dá ênfase ao caráter subjetivo do objeto investigado e estuda particularidades e experiências individuais dos participantes.

Utilizamos entrevistas semiestruturadas para identificar o significado das aulas de balé e as contribuições dessa atividade na qualidade de vida das alunas da instituição. Através da entrevista é que as entrevistadas colocam os seus pontos de vista a respeito do que "sabem, creem, esperam, sentem ou desejam, pretendem fazer, fazem ou fizeram e também acerca de suas explicações e razoes a respeito de coisas anteriores" (GIL, 1987, p.75) e se expressam mais livremente sobre sua participação nas aulas de balé sênior e das contribuições dessa atividade para a sua vida.

Apresentamos, a seguir, a resposta das onze alunas participantes da entrevista semiestruturada, composta de duas perguntas: Como você se sente desde que começou a frequentar as aulas de balé? Quais as contribuições que as aulas de balé trouxeram para sua vida? As alunas são identificadas pela idade, a fim de que não sejam identificadas pelos nomes.

\section{RESULTADOS E ANÁLISES}


Iniciamos a entrevista com a pergunta para saber como as alunas se sentem desde que começaram a frequentar as aulas de balé, e todas relataram estarem sentindo-se realizadas. Relativamente aos sentimentos proporcionados pelas aulas de balé, Marbá (2016 p.3) explica que “a dança é uma atividade física alegre que trás sensações de bem- estar e dá estímulos para a pessoa que a pratica. Essa prática de atividade leva o indivíduo a ter mais motivação, autoestima e autodeterminação".

"Me sinto realizada fazendo parte desse grupo de dança, amo dança e pra mim esta sendo uma nova experiência dançar balé" (71 anos).

"Estou me sentindo realizada. É um sonho subir no palco para dançar" (74 anos). "É uma realização e agora, nesta idade, um desafio pessoal" (70 anos).

"Estou amando a dança. Sempre achei lindo, mas nunca tive a oportunidade de dançar"

(60 anos).

"Estou me realizando na dança coreografada que sempre achei muito linda. e também é uma verdadeira terapia apesar de ser difícil, mas eu devo, eu quero, eu posso! Estou amando dançar" (63 anos). “As aulas de balé significa realizar meu sonho de ser, nesta idade, bailarina!” (65 anos).

Sobre as contribuições que as aulas de balé trouxeram para a vida das alunas, Marbá (2016, p.4) explana que "a dança é uma atividade física que melhora a saúde, pode desencadear vários benefícios e melhora o estilo de vida do indivíduo, independentemente da idade, e é uma excelente promotora da qualidade de vida".

“Acabei de me aposentar e estou amando as aulas. Eu amo dançar e quando me matriculei na UMI descobri que havia dança e já comecei a fazer aula. É gratificante, é maravilhoso, é um desafio nesta idade. Minhas netas ficaram felizes de ver a vovó dançando ballet" (63 anos).

"Sempre quis aprender a dançar, mas sempre ouvi que eu era sem ritmo e desengonçada para a dança. Na UMI fui bem acolhida e estou conseguindo superar minha falta de jeito pra dança. Meu sonho é dançar um anoite toda até desmontar de cansada” (54 anos). 
As aulas de balé clássico em uma universidade da melhor idade em Campo Grande - MS

"Como sempre digo, agora vou enfrentar todos os desafios e um deles é perder a timidez e me apresentar em um palco. Faço teatro e dança. Estou surpreendendo a mim mesma quando

$$
\text { vejo as filmagens" (59 anos). }
$$

"Dançar sempre fez parte da minha vida, pois sou da geração dos anos 70 e 80, dançava muito (risos). Hoje estou tendo a oportunidade de reviver tudo isso e muito mais. A dança coreografada que me possibilita trabalhar corpo e mente. Quero dançar até que todos os problemas da minha vida desapareçam ou se cansem de me ver feliz" (56 anos). "Sempre fui criticada por não saber dançar. Gosto muito de ver os outros dançar. Agora tenho essa oportunidade e não vou deixar passar. Quero aprender a dançar sim” (67 anos). Percebemos, através dos relatos das alunas, que as aulas de balé contribuíram de forma positiva na vida das alunas que participam das aulas, por ser uma "atividade física que melhora a disposição para as atividades do dia-a-dia pode proporcionar ao indivíduo que a prática, força muscular, estética corporal e autoestima, através dos movimentos realizados por tal atividade" (Marbá, 2016, p. 1).

\section{CONSIDERAÇÕES FINAIS}

Todas as alunas declararam estar realizando um sonho de menina, sentindo-se mais "Jovens", que perderam a timidez e sentiram-se acolhidas nas aulas de balé na UMI. O maior fator de satisfação citado por elas foi o de subir em um palco e apresentar as coreografias aprendidas durante as aulas.

\section{REFERÊNCIAS}

ACHCAR, Dalal. Ballet: Arte, Técnica e Interpretação. Rio de Janeiro: Cia. Brasileira de Artes Gráficas, 1980.

CACHIONI, M. Quem educa os idosos? Um estudo sobre professores de Universidade da Terceira Idade. Campinas, SP: Editora Alínea, 2003.

FERREIRA, Roberta Miranda, et. al. Balé adaptado: efeitos sobre as aptidões físicas em idosas. Revista Brasileira de Prescrição e Fisiologia do Exercício, São Paulo, v.3, n.14, p.196-203. Março/Abril. 2009.

GIL, A. C. Métodos e técnicas de pesquisa social. São Paulo: Atlas, 1987.

HASS, Aline Nogueira e GARCIA, Ângela. Ritmo e dança. Canoas. Ed. ULBRA, 2006. 
As aulas de balé clássico em uma universidade da melhor idade em Campo Grande - MS

LEAL, Indara Jubin. HAAS, Aline Nogueira. O significado da dança na terceira idade. Revista Brasileira de Ciências do Envelhecimento Humano, Passo Fundo, 64-71 - jan./jun. 2006.

MARBÁ, et. al. Dança na promoção da saúde e melhoria da qualidade de vida. Revista Científica do ITPAC, Araguaína, v.9, n.1, Pub.3, Fevereiro 2016.

MARTINS, G. A. F. As Aulas de Ballet Clássico no desempenho de Atletas de Ginástica Olímpica: Solo. The FIEP Bulletin, v. 84, p.283 - 288, 2014. R. F.

WITTER, Carla, et.al. Envelhecimento e dança: análise da produção científica na Biblioteca Virtual de Saúde. Rev. Bras. Geriatr. Gerontol. Rio de Janeiro, 2013; 16(1):191-199. 